\title{
Analysis and Suppression of Back-Flow Lightning Surges in Onshore Wind Farms
}

\author{
Ebrahim A. Badran*, Mohammad E. M. Rizk, and Mansour H. Abdel-Rahman \\ Electrical Engineering Department, Faculty of Engineering, Mansoura University, Mansoura, Egypt
}

\begin{abstract}
The rapid expansion of wind power generation has brought problems involving lightning strikes to the fore. Many such incidents have damaged not only the wind turbine that was actually struck, but also other turbines that were not. The phenomenon of surge invasion to the distribution line is categorized as "back-flow surge". It has been reported that this back-flow surge sometimes burns out surge arresters or breaks low-voltage circuits even far from the point of the lightning-struck.

In this paper, an analysis of the back-flow lightning surge phenomenon is presented for two wind turbines connected to the grid using the PSCAD/EMTDC. This analysis is implemented for two different lightning surges. The analysis considers the nonlinearity of the grounding system of the wind farm and the point on voltage wave when the surge strikes the wind tower. This paper investigates the effect of a proposed addition grounding grid for each wind tower on the suppression of back-flow lightning surge in the onshore wind farm.

The results demonstrate the effect of the grounding system nonlinearity and the effect of changing the point on voltage wave when the lightning surge strikes the wind tower on the back-flow surge phenomenon. The results show that the addition of a grounding grid for each wind tower highly decreases the bad effects of the back-flow lightning surge on the surge arresters.
\end{abstract}

Keywords: Back-flow surge, lightning, wind turbines (WT), grounding rods, PSCAD/EMTDC.

\section{INTRODUCTION}

Wind turbines are the fastest growing source of electrical energy with annual growth rates of about $30 \%$ in recent years, worldwide growth [1]. They are very exposed to lightning due to their large heights of towers, long rotating blades and windy locations $[1,2]$. In the literature, most researches have widely discussed important problems due to lightning strikes that face the wind towers and blades [3-7].

However a another serious problem known as "back-flow surge" which not only causes damages to the wind turbine that has been struck but also the other turbines that have not. The back-flow surge phenomenon has been defined in [8] as the surge flowing from a customer's structure such as a communication tower into the distribution line. The phenomenon of surge invasion from a wind turbine that is struck by lightning to the distribution line in a wind farm is quite similar to the case of "back-flow surge" $[9,10]$.

According to the investigation of lightning-caused failures, about $50 \%$ of the arrester failures are due to lightning back flow current so it should be considered as one of the main causes of distribution arrester failures [8].

Several breakdown and burnout incidents in low-voltage circuits and surge arresters at wind farms are thought to be the result of the back-flow surge $[9,10]$.

*Address correspondence to this author at the Electrical Engineering Department, Faculty of Engineering, Mansoura University, Mansoura, Egypt; Tel: +20-11-1109383; Fax: +20-50-2244690;

E-mail: ebadran@mans.edu.eg
Although [9] and [10] have presented analysis to the backflow surge phenomenon, the nonlinearity nature of the ground has not been introduced. If the current through the grounding resistance exceeds a certain limit; the value of the grounding resistance will not be constant as it will be dependent on the current flowing through it [13]. The back-flow surge flows backward from the grounding system of the actually struck wind turbine to the distribution lines between the WTs through the surge arresters. Therefore, the ground nonlinearity is an important issue for the analysis of the back-flow surge phenomenon in wind farms. This phenomenon does not only cause damage in the surge arresters at the wind turbines (WTs) that has been actually struck, but also causes damages in the surge arresters of the other WTs. This can be attributed to the propagation of this surge along the distribution lines between WTs. The instant when the lightning surge strikes the wind tower is also investigated in this paper.

In this paper, the back-flow surge phenomenon is investigated for two wind turbines connected to each other and to the grid by overhead distribution lines for two different lightning surges. The investigation considers changing the instant when the lightning surge strikes the wind tower (i.e. the point on voltage wave when the surge strikes the wind tower) and the grounding system nonlinearity of the wind farm. Finally, the effect of considering a proposed grounding grid for each wind tower on the suppression of the back-flow surge phenomenon is also investigated.

\section{WIND FARM DESCRIPTION AND MODELING}

The model of the wind farm is shown in Fig. (1) which consists of two identical wind turbines. Each wind turbine 


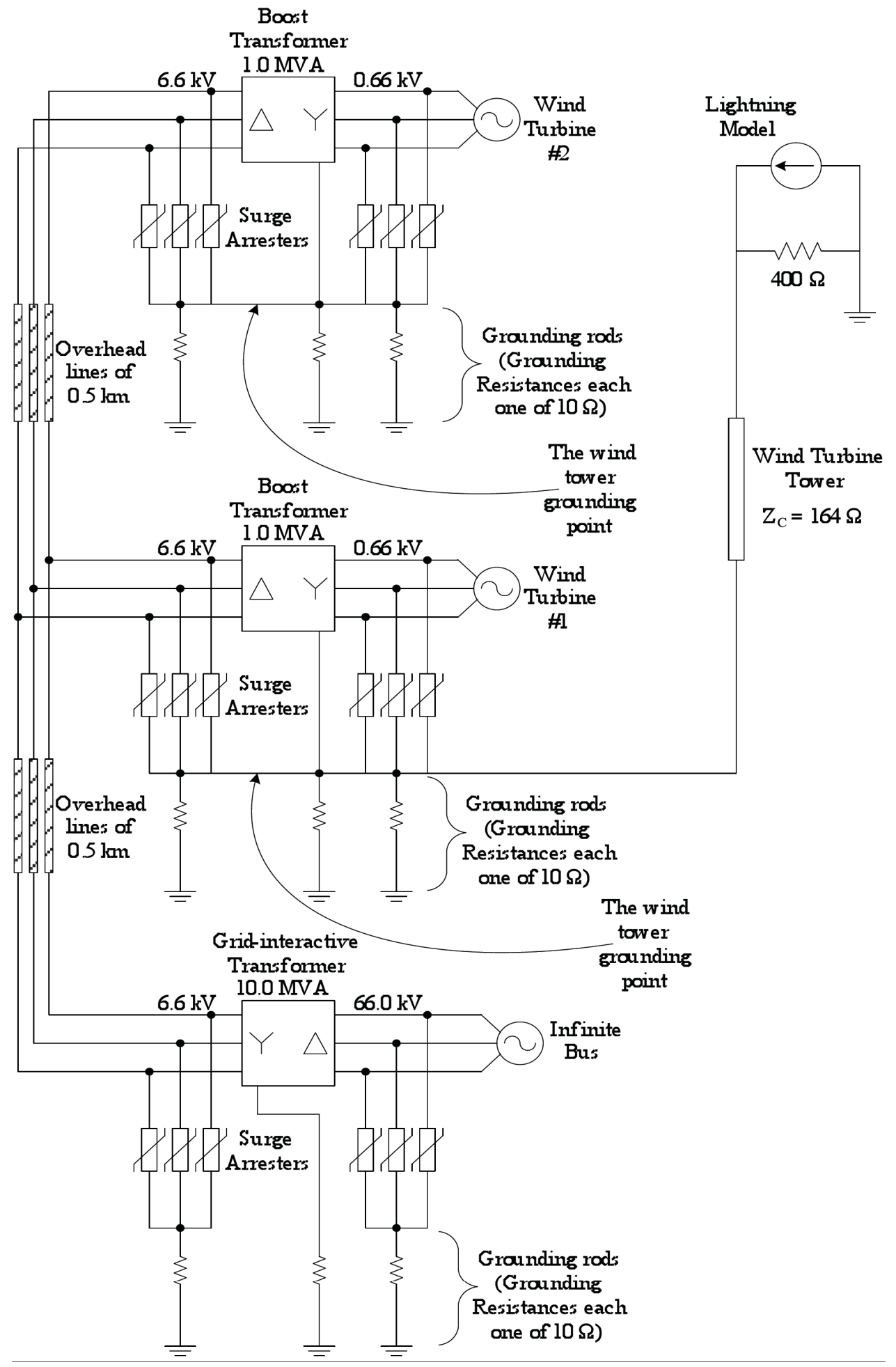

Fig. (1). The Onshore Wind Farm Configuration.

generator is connected to boost transformer. The two boost transformers are connected to the grid via grid-interactive transformer. Both boost transformers and grid-interactive transformer are connected to each other by overhead distribution lines. The grounding resistance which is determined by the current distribution within the buried grounding rod and the soil in the wind farm is estimated as $10.0 \Omega$ [9]. The PSCAD/EMTDC is used for modeling the wind farm as illustrated in the following paragraphs.

\subsection{Wind Turbines' Generators and Transformers Model}

Table 1 gives the required data for modeling the generators of the wind turbines and also, the transformers.

\subsection{Lightning Surge Modeling}

In this paper, two lightning surges are used in the investigation. Each lightning surge is simulated as controlled 
current source in the form of two slope ramps. The first lightning surge is the winter lightning in Japan $[9,10]$ while the second lightning surge directly strikes towers [15]. Table 2 gives the characteristics of each lightning surge.

\subsection{Surge Arrester Modeling}

In order to provide a protection from surge invasion, it is assumed that surge arresters are installed at both sides of each transformer $[9,10]$. The surge arresters used in this model are rated at $2.5 \mathrm{kA}$ and have a thermal limit of $15 \mathrm{~kJ}$. The surge arresters are modeled as a nonlinear resistance with the V-I characteristics given in [9] and reformulated to match with the PSCAD/EMTDC data type as given in Table 3. The burnout of an arrester occurs when the heat produced by the current flowing through the arrester exceeds its thermal limit.

Table 1. Wind Turbines and Transformers Data

\begin{tabular}{|c|c|}
\hline \multicolumn{2}{|c|}{ Wind Turbine Model (Synchronous Generator - Star Connected) } \\
\hline \hline Voltage (line rms) & $0.660[\mathrm{kV}]$ \\
\hline Rated power & $1.0[\mathrm{MVA}]$ \\
\hline Leakage reactance & $0.1[\mathrm{H}]$ \\
\hline Frequency & $60.0[\mathrm{~Hz}]$ \\
\hline Transformer Model (Boost, Grid-Interactive) \\
\hline \hline Connection method & $\mathrm{Y} / \Delta, \Delta / \mathrm{Y}$ \\
\hline Voltage (line rms) & $0.660 / 6.6[\mathrm{kV}], 66.0 / 6.6[\mathrm{kV}]$ \\
\hline Rated power & $1.0[\mathrm{MVA}], 10.0[\mathrm{MVA}]$ \\
\hline Leakage reactance & $0.15[\mathrm{p} . \mathrm{u}]$ \\
\hline Copper losses & $0.005[\mathrm{p} . \mathrm{u}]$ \\
\hline No-load losses & neglected \\
\hline
\end{tabular}

Table 2. Lightning Surges Characteristics

\begin{tabular}{|c|c|c|c|}
\hline & $\begin{array}{c}\text { Crest Peak } \\
{[\mathbf{k A}]}\end{array}$ & $\begin{array}{c}\text { Front Time } \\
{[\boldsymbol{\mu} \mathrm{sec}]}\end{array}$ & $\begin{array}{c}\text { Tail Time } \\
{[\boldsymbol{\mu} \mathrm{sec}]}\end{array}$ \\
\hline \hline Lightning surge \#1 & 51.0 & 2.0 & 631.0 \\
\hline Lightning surge \#2 & 200.0 & 10.0 & 100.0 \\
\hline
\end{tabular}

\subsection{Overhead Distribution Lines Modeling}

The frequency dependent phase model is used for the overhead distribution lines because this model is highly recommended for the analysis of very fast transient phenomena like lightning surges $[11,12]$.

Fig. (2) shows the geometric configuration of the overhead distribution lines. Moreover, Table 4 gives the required data for modeling the overhead distribution lines in PSCAD/EMTDC.

\section{LIGHTNING AND BACK-FLOW LIGHTNING SURGE'S STUDY}

In this section, the analysis of the back-flow surge phenomenon is performed for lightning surge \#1. The current and consumed energy within the surge arresters are investigated at two cases of different instances when the lightning surge strikes WT\#1. The first case when the lightning surge strikes at the negative peak point of phase A voltage wave. The second case when the lightning surge strikes at the positive peak point of phase A voltage wave. Moreover, the maximum potential rise on the grounding resistance is investigated. In this study, it is assumed that the lightning surge strikes directly the nearest wind turbine to the grid (i.e. WT\#1).

Table 3. The V-I Characteristics of the Surge Arresters

\begin{tabular}{|c|c|}
\hline Voltage $[\mathbf{k V}]$ & Current [kA] \\
\hline \hline 8.0 & 0.000001 \\
\hline 10.0 & 0.001 \\
\hline 11.053 & 0.01 \\
\hline 13.158 & 0.1 \\
\hline 14.9 & 1.0 \\
\hline 17.37 & 3.1623 \\
\hline 20.0 & 10.0 \\
\hline 21.905 & 17.7828 \\
\hline 22.28 & 21.54435 \\
\hline 25.0 & 46.4159 \\
\hline 30.0 & 100.0 \\
\hline
\end{tabular}

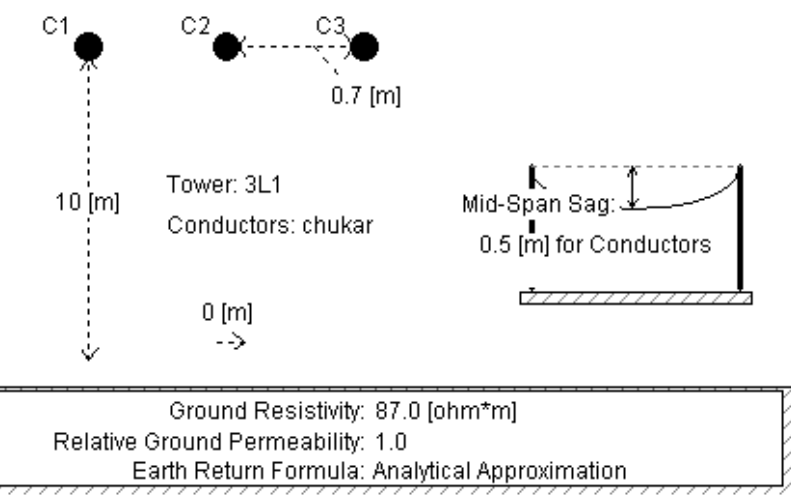

Fig. (2). Model of Wind Farm Distribution Line in PSCAD/ EMTDC.

Table 4. 6.6 kV Overhead Distribution Lines Data

\begin{tabular}{|c|c|}
\hline Height of all conductors & $10.0[\mathrm{~m}]$ \\
\hline Configuration of conductors & horizontal \\
\hline Spacing between phases & $0.7[\mathrm{~m}]$ \\
\hline Conductor radius & $0.0203454[\mathrm{~m}]$ \\
\hline Conductor d.c. resistance & $0.03206[\mathrm{ohm} / \mathrm{km}]$ \\
\hline Sag for all conductors & $0.5[\mathrm{~m}]$ \\
\hline Ground resistivity & $87.0[\Omega . \mathrm{m}]$ \\
\hline
\end{tabular}


Fig. (3) shows the current waveforms for lightning surge \#1 case through phase A surge arresters on $6.6 \mathrm{kV}$ side at WT\#1, WT\#2, and the grid. The surge current flows backward through the surge arresters from the grounding point of the directly struck wind turbine (i.e. WT\#1) to the overhead distribution lines. The surge current propagates through the overhead distribution lines and strikes WT\#2 boost transformer and the grid-interactive transformer. So, the surge current flows forward from the distribution lines to the grounding point through the surge arrester on $6.6 \mathrm{kV}$ side at $\mathrm{WTH} 2$ and the grid.

From Fig. (3), it is clear that the magnitude of surge current through phase A surge arrester on $6.6 \mathrm{kV}$ side at WT\#1 at the negative peak case is more than the surge current magnitude at the positive peak case. This can be attributed to that the lightning surge current is divided at the grounding point at WT \#1 between two paths; the grounding resistances and the surge arresters as shown in Fig. (1). The potential of phase A at its negative peak point is much less than the grounding potential which is in contrast of the positive peak point of phase A voltage. So the surge current which flows through phase A surge arrester is more in the negative peak of phase A case.
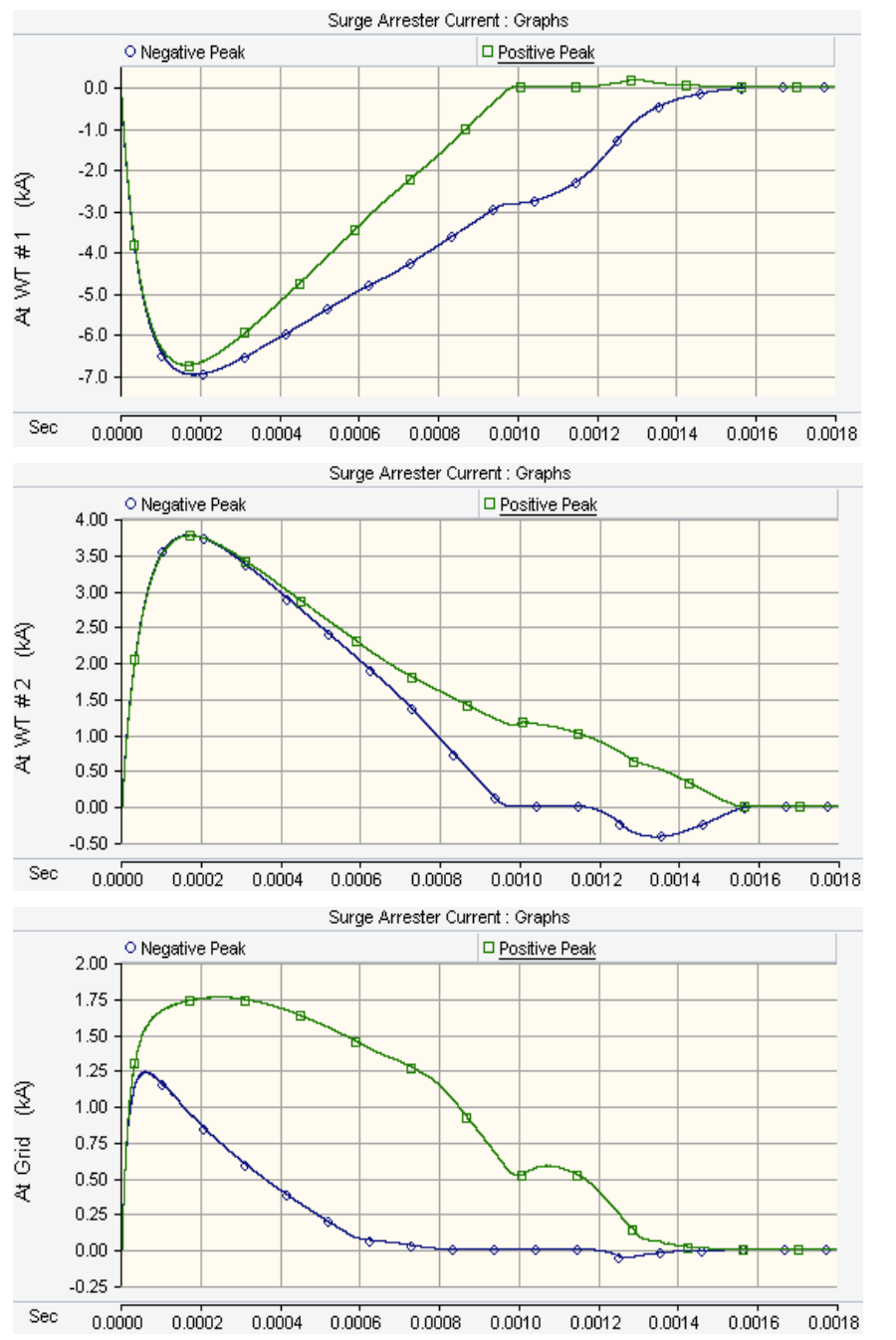

Fig. (3). Current Waveforms Through phase A Surge Arresters on $6.6 \mathrm{kV}$ Side for Lightning Surge \#1 Case.
Also, it is shown that the surge current in the arrester of WT\#1 is the largest because it is the actually struck wind turbine. The surge current in the arrester of WT\#2 is greater than that of the grid because of the delta connection of 6.6 $\mathrm{kV}$ winding of WT\#2 boost transformer and star earthed connection of $6.6 \mathrm{kV}$ winding of grid inter-active transformer. This can be attributed to that the delta connection has no path to the ground, so all the surge current flows through the surge arresters on $6.6 \mathrm{kV}$ side of WT\#2 boost transformer. Whereas, the star earthed has a path to the ground, so the surge current is divided between this path and the surge arresters on $6.6 \mathrm{kV}$ side of the grid-interactive transformer.

Furthermore, it is clear that, the surge current waveform through phase A surge arrester at WT\#2 for positive peak case is retarded beyond its for negative peak case while decreasing to zero. This is due to that the negative polarity of phase A has a tendency to draw current unlike the positive polarity.

It is clearly seen that, the magnitude of surge current through phase A surge arrester on $6.6 \mathrm{kV}$ side at grid for positive peak case is more than the surge current magnitude for negative peak case. This can be attributed to that the lightning surge current is divided at the connecting point between the phase A surge arrester and phase A winding of $6.6 \mathrm{kV}$ side (star earthed connection) of the grid-interactive transformer. For positive peak case, the magnitude of surge current that flows through phase A winding to earth is much less than that for negative peak case. Therefore, the magnitude of surge current through phase A surge arrester is more for positive peak case.

Table 5 demonstrates the maximum potential rise on the grounding point of the surge arresters on $6.6 \mathrm{kV}$ side for lightning surge \#1. It is shown that the maximum potential rise is the same for the different two cases of negative peak and positive peak of phase A voltage wave because surge arresters of the three phases are grounded at the same point as shown in Fig. (1).

Table 5. Max. Potential Rise on the Grounding Point for Lightning Surge \#1

\begin{tabular}{|c|c|c|}
\hline & At Negative Peak & At Positive Peak \\
\hline \hline At WT \#1 & $166.423 \mathrm{kV}$ & $166.423 \mathrm{kV}$ \\
\hline At WT \#2 & $37.633 \mathrm{kV}$ & $37.633 \mathrm{kV}$ \\
\hline At Grid & $42.417 \mathrm{kV}$ & $42.417 \mathrm{kV}$ \\
\hline
\end{tabular}

Fig. (4) shows the consumed energy for lightning surge $\# 1$ case in phase A surge arresters on $6.6 \mathrm{kV}$ side at WT\#1, WT\#2, and the grid. It is clear that, the consumed energy in the surge arresters exceeds its thermal limit, so the surge arresters are burnt out.

\section{BACK-FLOW LIGHTNING SURGE'S INVESTI- GATION CONSIDERING THE GROUNDING RESIS- TANCE NONLINEARITY}

In this section, the analysis of the back-flow Lightning surge phenomenon is performed for lightning surge \#2. The current and consumed energy within the surge arresters are 
investigated at two cases of different instances when the lightning surge strikes WT\#1 (i.e. positive peak and negative peak on phase A voltage wave). Moreover, the maximum potential rise on the grounding resistance is investigated. Also, it is assumed that the lightning surge strikes directly the nearest wind turbine to the grid (i.e. WT\#1).

There are two different models for the grounding resistance in this paper. The first model is the linear model of grounding resistance which is based on a constant value for the grounding resistance (i.e. $10 \Omega$ ) as given in the analysis in section III. The other model is based on the nonlinear performance of the grounding resistance with high currents. In this section, the ground nonlinearity behavior is investigated because it is important for back-flow surge analysis. As back-flow surge analysis requires more accurate modeling of the grounding system because the surge current back flows from the grounding through the surge arresters.

In this investigation, it is assumed that the used soil medium is homogeneous and of a typical soil resistivity. The grounding resistance decreases as the discharge current value through it increases beyond a certain value. This is due to the ionization of the soil surrounding the buried ground rods. The nonlinearity nature of the ground resistance can be represented by a nonlinear resistance, $R_{T}$, whose value is given as [13];

$R_{T}=R_{0} \sqrt{1+\left(I / I_{g}\right)} \quad$ for $\quad I>I_{g}$

$I_{g}=\left(E_{0} \times \rho\right) / 2 \pi \times R_{0}^{2}$

where, $R_{o}$ is the grounding resistance for currents less than $I_{g}$ (i.e. $10 \Omega$ ), $\rho$ is the soil resistivity, $E_{o}$ is the ionization electric field of the soil, and $I_{g}$ is the critical current for soil ionization [13]. The physical characteristics of soil are given in [14] as:

$\rho=87[\Omega \cdot m], E_{0}=127[\mathrm{kV} / \mathrm{m}], \varepsilon_{r}=8, \mu_{r}=1$.

Thus, the nonlinearity characteristics of the grounding resistance appear when the current flows through the grounding resistance exceeds the critical value of $17.585 \mathrm{kA}$. Through section III investigations it is found that, the maximum grounding potential rise is $166.423 \mathrm{kV}$ which mean that the current through the grounding resistance of 10 $\Omega$ is $16.6423 \mathrm{kA}$. This value is lower than the critical value of current, so the nonlinearity of the grounding resistance doesn't appear in the analysis of back flow surge for surge $\# 1$.

Fig. (5) shows the current waveforms for lightning surge \#2 case through phase A surge arresters on $6.6 \mathrm{kV}$ side at $\mathrm{WT} \# 1, \mathrm{WT} \# 2$, and the grid. It is assumed that the grounding resistance is linear (i.e. its value is constant at $10 \Omega$ ).

Table 6 demonstrates the maximum potential rise on the grounding point of the surge arresters on $6.6 \mathrm{kV}$ side for lightning surge \#2 assuming linear grounding resistance. It is shown that the maximum potential rise is the same for the two cases of negative peak and positive peak of phase A voltage wave. From Table 6, it is clear that the surge current through the grounding resistance at WT\#1 reaches 62.9815 $\mathrm{kA}$ which is $358.155 \%$ of the critical current for soil ionization. So, the linear model for the grounding resistance at WT\#1 for lightning surge \#2 case is not accurate.

Fig. (6) shows the consumed energy for lightning surge \#2 case in phase A surge arresters on $6.6 \mathrm{kV}$ side at WT\#1, $\mathrm{WT} \# 2$, and the grid assuming linear grounding resistance. It is clear that, the consumed energy in the surge arresters exceeds its thermal limit, so the surge arresters are burnt out.

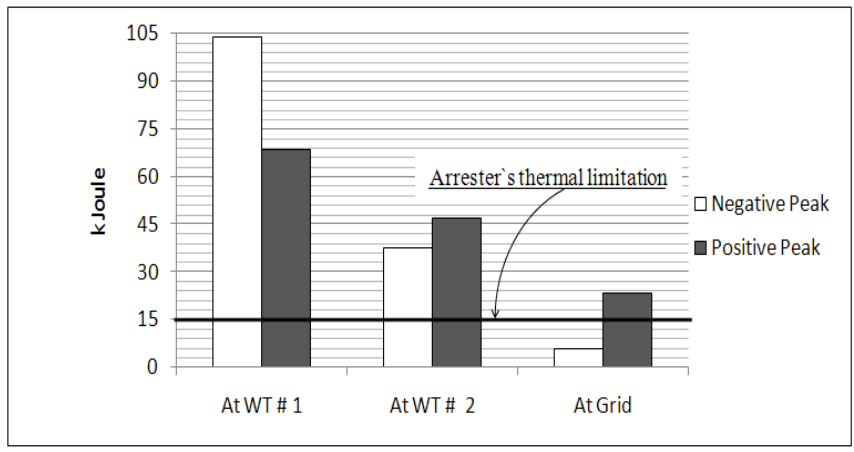

Fig. (4). Consumed Energy in Phase A Surge Arresters on $6.6 \mathrm{kV}$ Side at Lightning Surge \#1 Case.

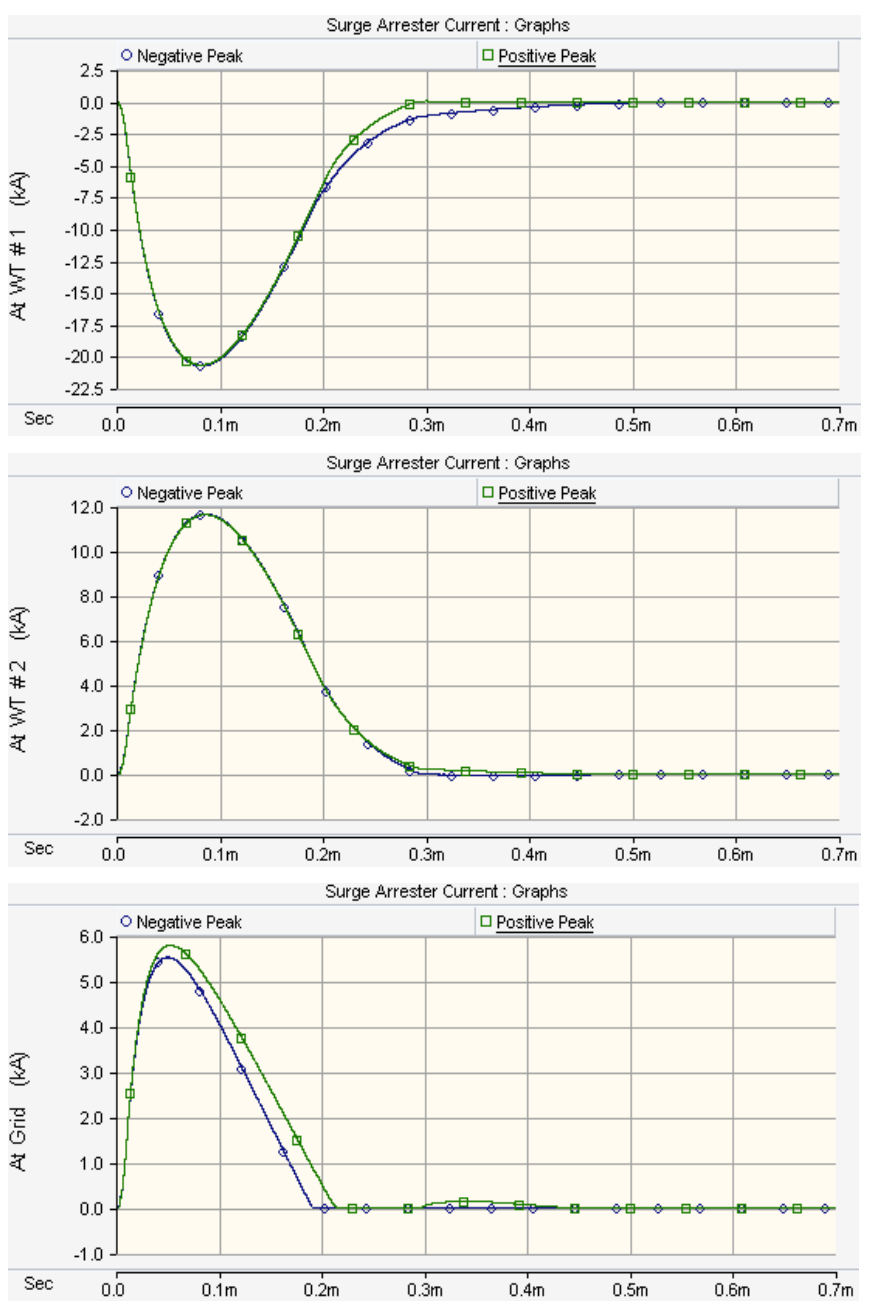

Fig. (5). Current Waveforms Through Phase A Surge Arresters on $6.6 \mathrm{kV}$ Side for Lightning Surge \#2 Case (Linear Grounding Resistance).

Fig. (7) shows the current waveforms for lightning surge \#2 case through phase A surge arresters on $6.6 \mathrm{kV}$ side at 
WT\#1, WT\#2, and the grid. In Fig. (7), it is assumed that the grounding resistance is nonlinear (i.e. its value is current dependent as has been described in equation 1). It is clear that, there is a significant effect of the nonlinearity behavior of the grounding resistance on the magnitude of surge current through the surge arresters. The decrease in the surge current magnitude through the surge arresters due to incorporating the nonlinearity behavior of the grounding resistance can be attributed to the decrease in the grounding resistance within the increase in surge current through it.

Table 6. Maximum Potential Rise on the Grounding Point for Lightning Surge \#2 (Linear Grounding Resistance)

\begin{tabular}{|c|c|c|}
\hline & At Negative Peak & At Positive Peak \\
\hline \hline At WT \#1 & $629.815 \mathrm{kV}$ & $629.815 \mathrm{kV}$ \\
\hline At WT \#2 & $116.357 \mathrm{kV}$ & $116.357 \mathrm{kV}$ \\
\hline At Grid & $169.463 \mathrm{kV}$ & $169.463 \mathrm{kV}$ \\
\hline
\end{tabular}

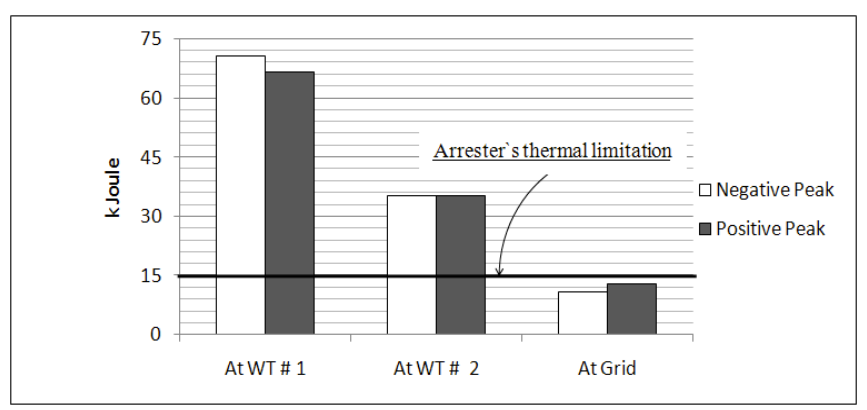

Fig. (6). Consumed Energy in Phase A Surge Arresters on $6.6 \mathrm{kV}$ side at Lightning Surge \#2 Case (Linear Grounding Resistance).

Table 7 demonstrates the maximum potential rise on the grounding point of the surge arresters on $6.6 \mathrm{kV}$ side for lightning surge \#2 assuming nonlinear grounding resistance. Also, it is shown that, the maximum potential rise is the same for the two cases of negative peak and positive peak of phase A voltage wave. From Table 7, it is clear that there is a significant decrease in the maximum potential rise on the grounding resistance at WT\#1 due to the decrease in its value as described in equation 1 . The decrease in the maximum potential rise on the grounding resistances at WT\#2 and the grid is due to the decrease in surge currents through them.

Fig. (8) shows the consumed energy for lightning surge \#2 case in phase A surge arresters on $6.6 \mathrm{kV}$ side at WT\#1, WT\#2, and the grid assuming nonlinear grounding resistance. The significant decrease in the consumed energy in the surge arresters is due to the significant decrease in surge currents through them. In spite of the decrease in the consumed energy in the surge arresters, it still exceeds its thermal limit so the surge arresters are burnt out.

\section{BACK-FLOW LIGHTNING SURGE'S SUPPRES- SION}

This section presents a proposed technique for the suppression of back flow lightning surge. This technique of suppression is applied by connecting the wind tower grounding point to an efficient grounding grid as shown in Fig. (9). The grounding grid consists of 12 buried grounding rods and these are connected to each other using hollow concentric insulated conductors.

Table 7. Maximum Potential Rise on the Grounding Point for Lightning Surge \#2 (Nonlinear Grounding Resistance)

\begin{tabular}{|c|c|c|}
\hline & At Negative Peak & At Positive Peak \\
\hline \hline At WT \#1 & $300.256 \mathrm{kV}$ & $300.256 \mathrm{kV}$ \\
\hline At WT \#2 & $73.591 \mathrm{kV}$ & $73.591 \mathrm{kV}$ \\
\hline At Grid & $96.484 \mathrm{kV}$ & $96.484 \mathrm{kV}$ \\
\hline
\end{tabular}
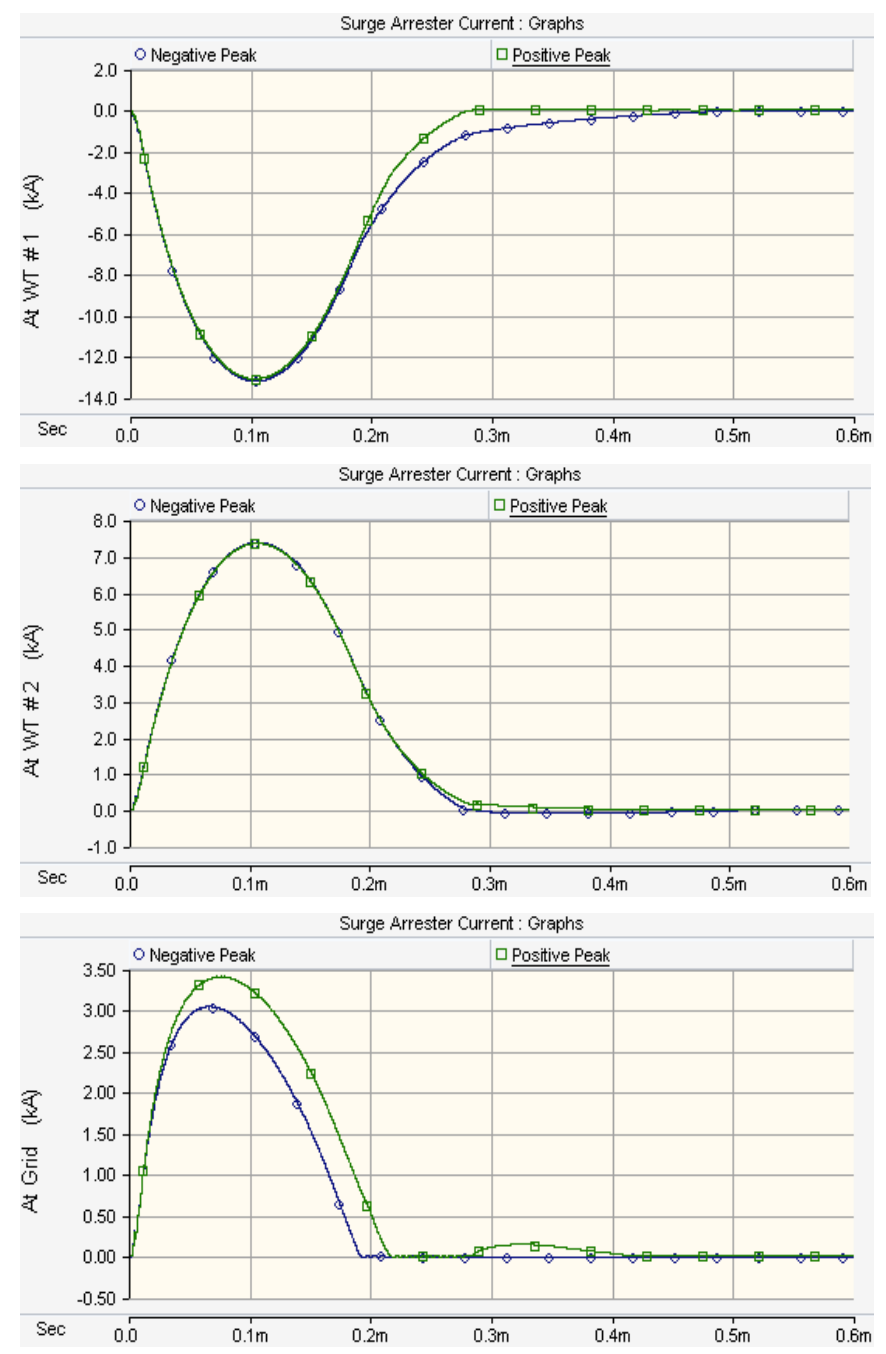

Fig. (7). Current Waveforms Through Phase A Surge Arresters on $6.6 \mathrm{kV}$ Side for Lightning Surge \#2 Case (Nonlinear Grounding Resistance).

The hollow concentric insulated conductors consist of steel core conductor for mechanical strength and two hollow concentric copper conductors as shown in Fig. (10). There are insulation layers surrounding the three parallel conductors (i.e. steel core and the two copper hollow conductors) as shown in Fig. (10). The conductors between the grounding rods are designed as steel-cored hollow insulated conductors to reduce the skin effect and to save in required volume of copper. 


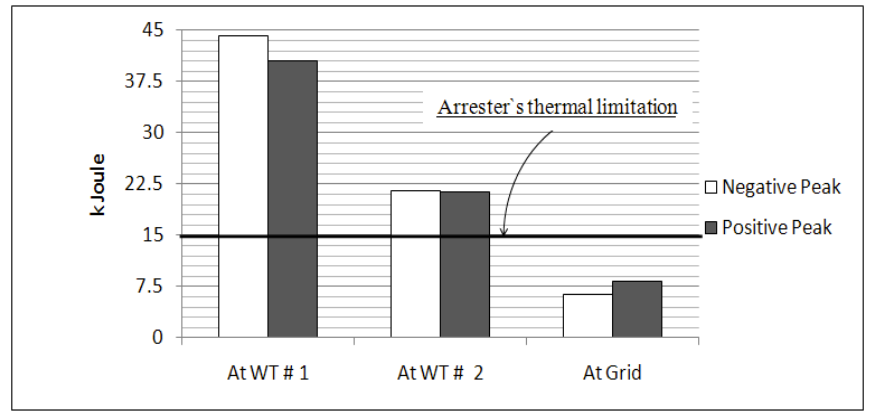

Fig. (8). Consumed Energy in Phase A Surge Arresters on $6.6 \mathrm{kV}$ Side at Lightning Surge \#2 Case (Nonlinear Grounding Resistance).

Fig. (11) shows the same current as in Fig. (3) but with connecting the proposed grounding grid to the grounding point of the wind towers. While, Fig. (13) shows the same current as in Fig. (7) but with connecting the proposed grounding grid to the grounding point of the wind towers. The results show that connecting the grounding point at each wind turbine to the proposed grounding grid shown in Fig. (9) results in a significant suppression for the lightning surge current through the surge arresters. This can be attributed to that the grounding grid at struck wind turbine (i.e. WT\#1) diverts the surge current away from the surge arresters.

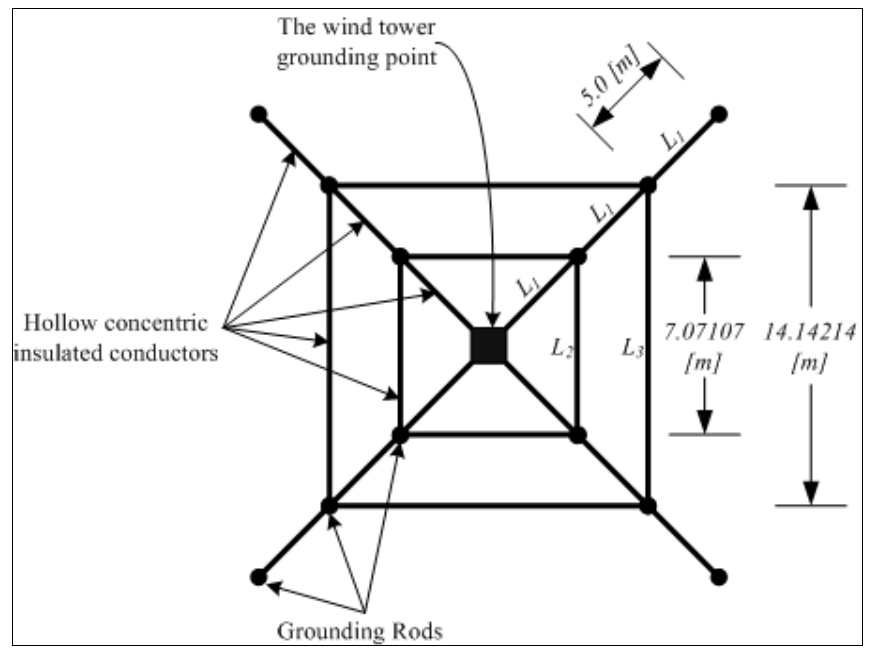

Fig. (9). The Proposed Grounding Grid for Each Wind Tower.

Fig. (12) shows the same energy as in Fig. (4) but with connecting the proposed grounding grid to the grounding point of the wind towers. While, Fig. (14) shows the same energy as in Fig. (8) but with connecting the proposed grounding grid to the grounding point of the wind towers. The results show that connecting the grounding point at each wind turbine to the grounding grid results in a significant decrease in the consumed energy in the surge arresters due to the high suppression in surge current through the surge arresters. The consumed energy in surge arresters becomes less than the thermal limit, so the surge arresters are protected against burning out.

Table 8 shows the same energy as in Table $\mathbf{5}$ but with connecting the proposed grounding grid to the grounding point of the wind towers. While, Table 9 shows the same energy as in Table 7 but with connecting the proposed grounding grid to the grounding point of the wind towers. The results show that there is a great decrease in the maximum potential rise on the grounding resistances due to the connecting of the proposed grounding grid.

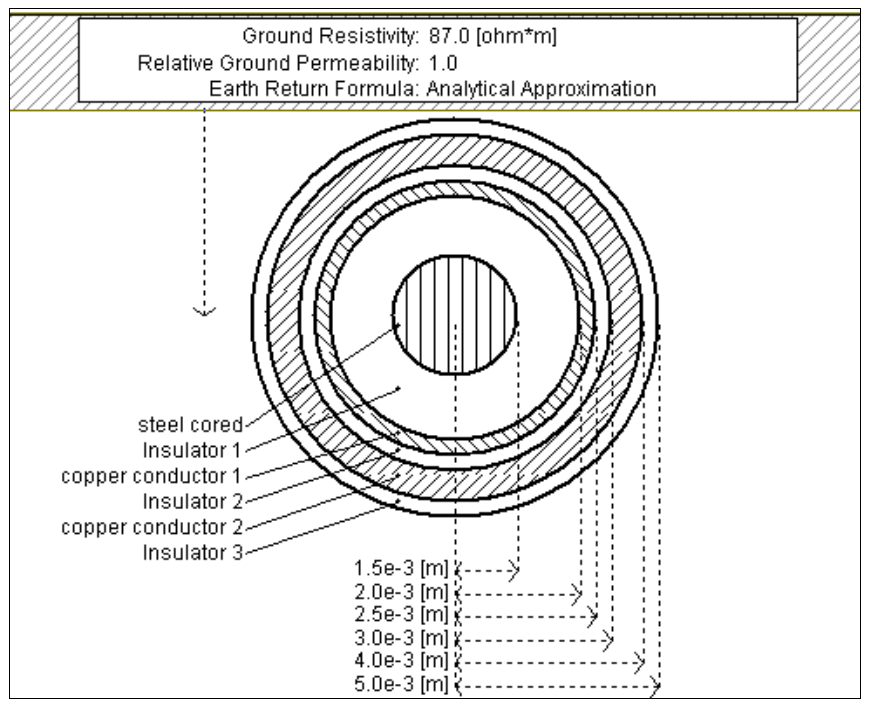

Fig. (10). The Configuration of Steel-Cored Hollow Concentric Insulated Conductors.

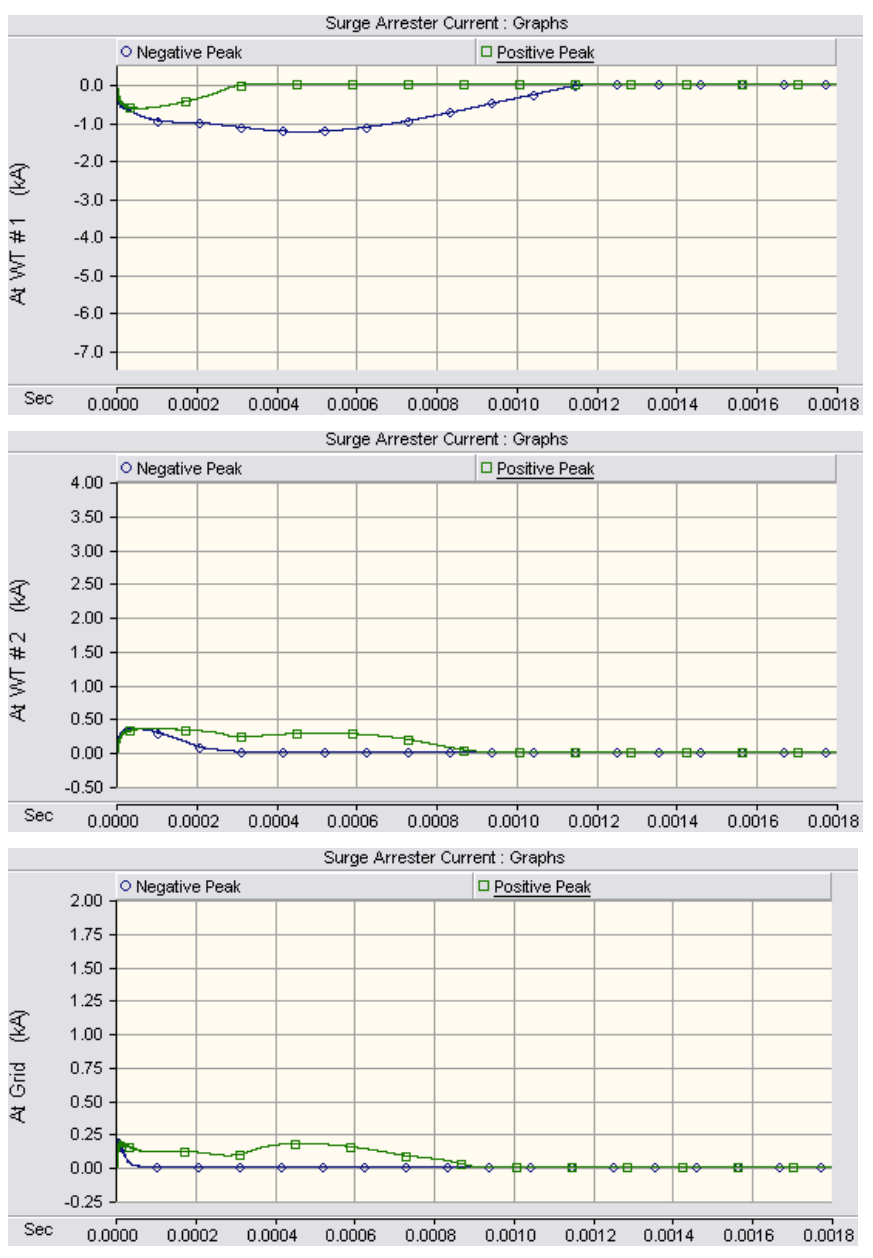

Fig. (11). Current Waveforms Through Phase A Surge Arresters on $6.6 \mathrm{kV}$ Side for Lightning Surge \#1 Case with the Proposed Grounding Grid. 


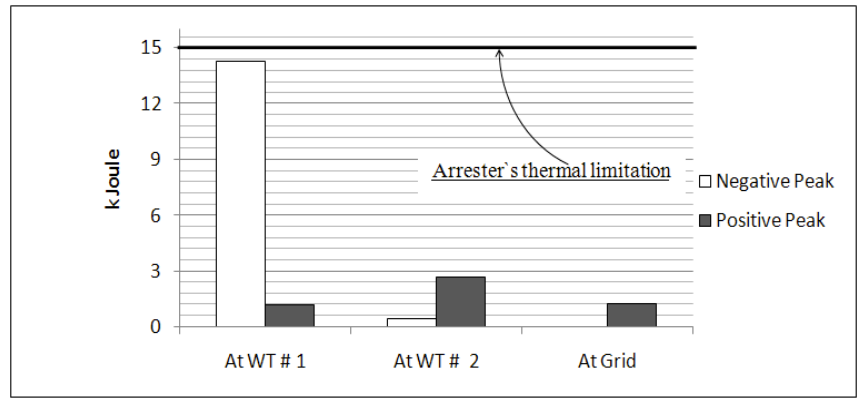

Fig. (12). Consumed Energy in Phase A Surge Arresters on $6.6 \mathrm{kV}$ Side at Lightning Surge \#1 Case with the Proposed Grounding Grid.

Table 8. Maximum Potential Rise on the Grounding Point for Lightning Surge \#1 Case with the Proposed Grounding Grid

\begin{tabular}{|c|c|c|}
\hline & At Negative Peak & At Positive Peak \\
\hline \hline At WT \#1 & $78.069 \mathrm{kV}$ & $78.069 \mathrm{kV}$ \\
\hline At WT \#2 & $2.325 \mathrm{kV}$ & $2.325 \mathrm{kV}$ \\
\hline At Grid & $3.196 \mathrm{kV}$ & $3.196 \mathrm{kV}$ \\
\hline
\end{tabular}

Table 9. Maximum Potential Rise on the Grounding Point for Lightning Surge \#2 Case with the Proposed Grounding Grid (Nonlinear Grounding Resistance)

\begin{tabular}{|c|c|c|}
\hline & At Negative Peak & At Positive Peak \\
\hline \hline At WT \#1 & $177.188 \mathrm{kV}$ & $177.188 \mathrm{kV}$ \\
\hline At WT \#2 & $22.598 \mathrm{kV}$ & $22.598 \mathrm{kV}$ \\
\hline At Grid & $28.825 \mathrm{kV}$ & $25.825 \mathrm{kV}$ \\
\hline
\end{tabular}

\section{CONCLUSION}

This paper presents an analysis of the back-flow lightning surge phenomenon which has serious drawbacks on the wind farms. The analysis is carried out on a wind farm consisting of two wind turbines for two different lightning surges. The analysis considers changing the instant when the lightning surge strikes the wind tower. The results show that the effect of changing the instant when the lightning surge strikes the wind tower is more significant for lightning surge \#1. Also, the nonlinearity behavior of the grounding system is investigated. The results show that there is a significant decrease in the current and absorbed energy in the surge arresters due to the grounding resistance nonlinearity.

The proposed method for the suppression of the backflow surge is implemented using an efficient grounding grid for each wind tower. The results show significant effect of the method on the suppression of back-flow surge. The proposed method significantly suppresses the surge currents through the surge arresters and consequently the absorbed energy in the surge arresters below their thermal limit.

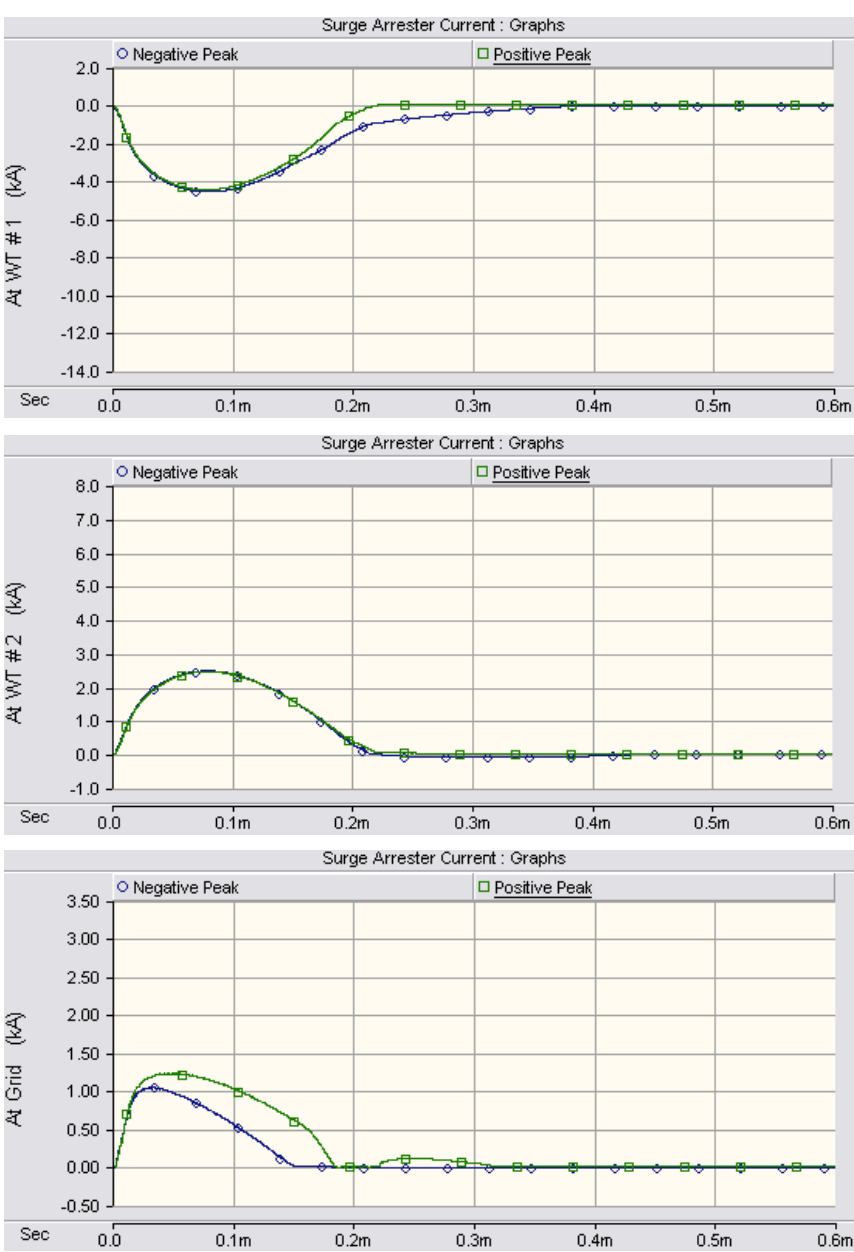

Fig. (13). Current Waveforms Through Phase A Surge Arresters on 6.6 kV Side for Lightning Surge \#2 Case with the Proposed Grounding Grid (Nonlinear Grounding Resistance).

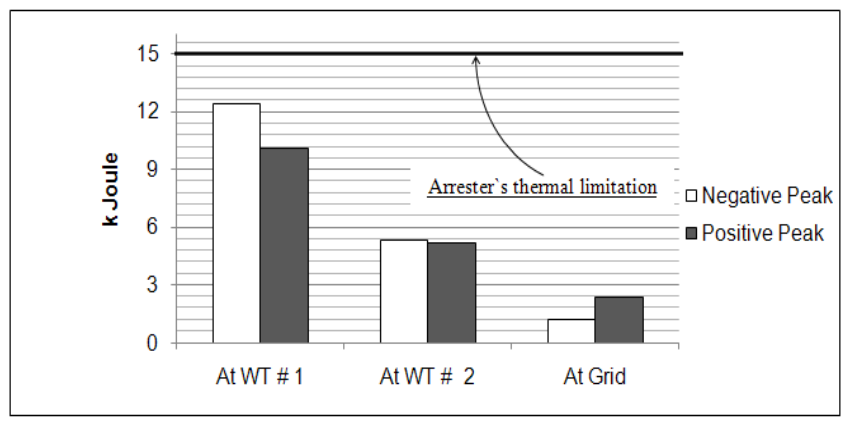

Fig. (14). Consumed Energy in Phase A Surge Arresters on $6.6 \mathrm{kV}$ Side at Lightning Surge \#2 Case with the Proposed Grounding Grid (Nonlinear Grounding Resistance).

\section{REFERENCES}

[1] Sorensen TS. The update of IEC 61400-24 lightning protection of wind turbines. In: $29^{\text {th }}$ International Conference on Lightning Protection, $23^{\text {rd }}-26^{\text {th }}$ June, Sweden 2008.

[2] Wind Turbine Generation System - 24: Lightning Protection. In: IEC Technical Report, TR61400-24, 2002.

[3] McNiff B. Wind Turbine Lightning Protection, Project report, 1999-2001. In: NREL Subcontractor Report, SR-500-31115, 2002.

[4] Ringleb U. Technical information lightning protection for wind turbines. Schunk-group, 2008 
[5] Rachidi F, Rubinstein M, Montanyà J, et al. A Review of Current Issues in Lightning Protection of New-Generation Wind-Turbine Blades of New-Generation Wind-Turbine Blades. IEEE Trans Ind Electron 2008; 55(6): 2489-96.

[6] Yoh Y. A New Lightning Protection System for Wind Turbines Using Two Ring-Shaped Electrodes. IEEJ Trans 2006; 1: 314-9.

[7] Lewke B, Kramer S, Méndez Hernández Y, Kindersberger J. Conductive surface layer on wind turbine blade as lightning protection system. In: Proceedings of Windpower, Los Angeles, 36 June, 2007, USA.

[8] Nakada K, Wakai T, Taniguchi $\mathrm{H}$, et al. Distribution arrester failures caused by lightning current following from Customer's Structure into Distribution Lines. IEEE Trans Power Deliv 1999; 14(4): 1527-6.

[9] Yasuda Y, Funabashi T. Analysis on Back-Flow Surge in Wind Farms. In: IPST'07, Lyon, France, June 4-7, 2007.
[10] Yasuda Y, Kobayashi H, Funabashi T. Surge analysis on wind farm when winter lightning strikes. IEEE Trans Energy Conversion 2008; 23(1): 257-6.

[11] Martinez JA, Gustavsen B, Durbak D. Parameter determination for modeling system transients part I: overhead lines. IEEE Trans Power Deliv 2005; 20(3): 2038-7.

[12] PSCAD/EMTDC User's Guide Eds. Manitoba HVDC Research Centre, 2005.

[13] Romero D, Montanyà J, Candela $\mathrm{A}$. Behaviour of the wind-turbines under lightning strikes including nonlinear grounding system. In: ICREPQ'04, Barcelona, 31 March, 1, 2 April, 2004.

[14] Ala G, Silvestre MLD, Viola F. Soil Ionization due to High Pulse Transient Currents Leaked by Earth Electrodes. Prog Electromagnet Res B 2009; 14: 1-21.

[15] Schmitt H, Winter W. Simulation of lightning overvoltages in electrical power systems. In: IPST '01 - Rio de Janeiro, June 24-28, Brazil 2001.

(C) Badran et al.; Licensee Bentham Open.

This is an open access article licensed under the terms of the Creative Commons Attribution Non-Commercial License (http://creativecommons.org/licenses/by-nc/ 3.0/) which permits unrestricted, non-commercial use, distribution and reproduction in any medium, provided the work is properly cited. 